\title{
MEMBANGUN SERVER VOIP BERBASIS ASTERISK
}

\author{
Berlian $^{1}$ \\ 1,2 DosenTetap Program Studi Informatika Fakultas Ilmu Komputer Universitas Dehasen Bengkulu \\ Jl. Meranti Raya No. 32 Kota Bengkulu 38228 Telp. (0736) 22027, 26957 Fax. (0736) 341139) \\ e-mail: berlian@unived.ac.id
}

\begin{abstract}
Voice Over Internet Protocol (VOIP) is a technology utilizing the Internet Protocol to provide the voice communication electronically and in real-time manner. VOIP technology is the recent telecommunication technology, in which the cost spent for this technology's infrastructure is much cheaper than other telecommunication technology commonly used by the public currently. Asterisk is a softswitch to operate the proxy based on the session initiation protocol (SIP). The 11.04 Ubuntu operating system as the VOIP served is flexible enough to support the asterisk package performance.

The objective of research is to build Asterisk based-VOIP server, in order to be developed in the future research according to the requirement. The research method employed mainly consisted of two ways: literary study and experiment. This research was done in the institution with the intranet network built previously. Thus, VOIP here function as the maximizer of existing intranet network to reduce the expenditure. for communication requirement. The service provided in this study include voice and video with the call client to server, call client to client, video call, conference and mailbox/voicemail services.

Keyword: VOIP, SIP, Asterisk, IP-PBX, Telephony..
\end{abstract}

Intisari - Voice Over Internet Protocol (VOIP) merupakan teknologi yang memanfaatkan Internet Protocol untuk menyediakan komunikasi voice secara elektronis dan real-time. Teknologi VOIP merupakan teknologi telekomunikasi masa kini, dimana biaya yang dikeluarkan untuk infrastruktur teknologi ini jauh lebih murah dibanding teknologi telekomunikasi yang umumnya digunakan masyarakat saat ini. Asterisk merupakan softswicth untuk mengoperasikan proxy, yang berbasis session initiation protocol (SIP). Sistem operasi Ubuntu 11.04 sebagai server VOIP cukup fleksibel untuk mendukung kinerja paket Asterisk.

Tujuan dari penelitian ini adalah membangun server VOIP berbasis Asterisk, agar dapat dikembangkan pada penelitian selanjutnya sesuai dengan kebutuhan. Metodologi penelitian yang dilakukan, secara garis besar terdiri dari dua alur. Yaitu studi literatur dan percobaan. Penelitian ini dilakukan pada jaringan intranet atau Local Area Network (LAN). Sehingga VOIP disini difungsikan sebagai pemaksimalan jaringan intranet yang sudah ada tersebut untuk menekan biaya pengeluaran kebutuhan komunikasi. Layanan yang disediakan pada penelitian ini berbentuk voice dan video dengan layanan call client to client, video call, conference dan mailbox/voicemail.

Kata Kunci: VOIP, SIP, Asterisk, IP-PBX, Telephony.

\section{PENDAHULUAN}

Perkembangan teknologi saat ini sudah demikian maju, terutama dalam bidang telekomunikasi. Masalah jarak dan waktu tidak lagi menjadi masalah dengan adanya perkembangan yang pesat dalam bidang telekomunikasi. Saat ini kita bisa melakukan percakapan jarak jauh dengan menggunakan media telepon. Media telepon saat ini menggunakan teknologi jaringan Public Switch Telephone Network (PSTN).

Jaringan PSTN melewatkan suara melalui media jaringan kabel khusus. Jaringan komunikasi data ini mengirimkan data suara (voice) berbasis circuit switch. Telepon langsung terhubung dengan PABX (Private Automated Branch Exchange) yang di dalamnya ada daftar nomor-nomor telepon yang disusun secara bertingkat sesuai dengan daerah cakupannya. Kekurangan dari media ini adalah biaya yang mahal untuk sambungan jarak jauh.

Voice Over Internet Protocol (VOIP) merupakan teknologi yang memanfaatkan Internet Protocol untuk menyediakan komunikasi voice secara elektronis dan realtime. Teknologi VOIP merupakan teknologi telekomunikasi masa kini, dimana biaya yang dikeluarkan untuk infrastruktur teknologi ini jauh lebih murah dibanding teknologi telekomunikasi yang menggunakan PSTN. Unsur pembentuk VOIP adalah User agent, Proxy, Protocol dan Coder-Decoder (CODEC).

Asterisk dan X-Lite merupakan software open source yang digunakan untuk membangun VOIP. Asterisk dapat berjalan di berbagai sistem operasi (Windows, Linux, Mac, OpenBSD dan FreeBSD). Juga memberi wewenang kepada pengembang dan pelaksana untuk membuat solusi berkomunikasi yang lebih baik dengan gratis..

\section{LANDASAN TEORI}

Jaringan komputer adalah kumpulan dua atau lebih komputer, printer dan peralatan lainnya saling 
berhubungan untuk melakukan komunikasi data. Informasi dan data bergerak melalui kabel-kabel (wire line) atau tanpa kabel (wireless). Sehingga memungkinkan pengguna jaringan komputer dapat saling bertukar dokumen dan data, mencetak pada printer yang sama dan bersama-sama menggunakan hardware/software yang terhubung dengan jaringan. Tiap komputer, printer atau peripheral yang terhubung dengan jaringan disebut node.

\section{A. Prinsip Dasar Jaringan Komputer}

Prinsip dasar dalam sistem jaringan komputer adalah proses pengiriman data atau informasi dari pengirim ke penerima melalui suatu media komunikasi tertentu. Sedangkan tujuan utama dibangunnya suatu jaringan komputer adalah untuk membawa data/informasi dari pengirim menuju penerima secara cepat dan tepat tanpa adanya kesalahan melalui media transmisi atau media komunikasi tertentu.

\section{B. Manfaat Jaringan Komputer}

Manfaat yang akan diperoleh dengan membuat jaringan komputer antara lain, yaitu :

1. Memberikan kesempatan kepada pengguna komputer untuk mempergunakan sumber daya secara bersama-sama, seperti penggunaan printer maupun memakai koneksi internet bersama.

2. Optimalisasi pemakaian perangkat sehingga tercapainya efisiensi seperti tidak perlunya masing-masing komputer dilengkapi dengan printer dikarenakan adanya jaringan sehingga 2 (dua) atau lebih komputer dapat mempergunakan 1 (satu) printer.

3. Komunikasi antar sistem operasi yang berbeda sehingga tidak perlu dalam sebuah jaringan komputer semuanya harus memakai sistem operasi yang sama.

Adapun manfaat yang dapat diperoleh dengan adanya jaringan, yaitu sebagai berikut :

1. Jaringan memungkinkan manajemen sumber daya efisien.

2. Jaringan membantu mempertahankan informasi agar tetap andal dan up to date.
3. Jaringan membantu mempercepat proses berbagi data.

4. Jaringan memungkinkan kelompok kerja agar dapat berkomunikasi dengan lebih efisien.

5. Jaringan membantu usaha dalam melayani klien mereka secara lebih efektif.

C. Area Jaringan Komputer

Berdasarkan jangkauan area jaringan dan luasan segmen jaringan yang dibangun maka suatu jaringan komputer dapat digolongan menjadi tiga kelompok yaitu :

1. LAN (Local Area Network)

Yang termasuk dalam kelompok jaringan ini adalah jika komputer-komputer yang terhubung berada dalam ruangan-ruangan dalam satu gedung.

2. MAN (Metropolitan Area Network)

Yang termasuk dalam kelompok MAN adalah jika komputer-komputer yang terhubung berada pada satu gedung dengan gedung yang lain tapi masih dalam satu kota.

3. WAN (Wide Area Network)

WAN merupakan pengembangan dari MAN, sehingga komputer-komputer yang terhubung berada pada gedunggedung yang berada pada kota yang berbeda bahkan berbeda negara.

\section{Model Koneksi Dalam Jaringan}

Ada dua model koneksi dalam jaringan, yaitu:

\section{Peer to Peer}

Sistem operasi jaringan model peer to peer memungkinkan seorang user membagi sumber daya yang ada dikomputernya, baik itu file data, printer, dan juga bisa mengakses sumber data pada komputer lain. Model ini tidak mempunyai sebuah file server atau sumber daya yang terpusat. Seluruh komputer mempunyai kemampuan yang sama untuk memakai sumber daya yang tersedia di jaringan.

\section{Client-Server}

Sistem operasi jaringan Client-Server memungkinkan jaringan untuk mensentralisasi fungsi dan aplikasi kepada satu atau dua dedicated file server. Sebuah file server menjadi jantung dari keseluruhan sistem, memungkinkan untuk mengakses sumber daya, dan menyediakan 
keamanan. Workstation-workstation dapat mengambil sumber daya yang ada pada file server.

\section{E. Topologi Jaringan Komputer}

Topologi adalah bagian yang menjelaskan hubungan antara komputer yang dibangun berdasarkan kegunaan, Keterbatasan resource dan keterbatasan biaya, berarti topologi-topologi jaringan yang ada biasa disesuaikan dengan keadaan dilapangan.

Topologi terdiri dari beberapa jenis antara lain sebagai berikut:

1. Topologi Bus

Topologi bus merupakan topologi yang banyak dipergunakan pada masa penggunaan kabel coaxial menjamur. Topologi ini memiliki karakteristik sebagai berikut:

a. Merupakan satu kabel yang kedua ujungnya ditutup, dimana sepanjang kabel terdapat nodenode.

b. Umum digunakan karena sederhana dalam instalasi.

c. Signal melewati kabel dalam dua arah dan mungkin terjadi collision.

d. Permasalahan terbesar pada saat kabel putus, jika salah satu segmen kabel putus, maka seluruh jaringan akan terhenti..

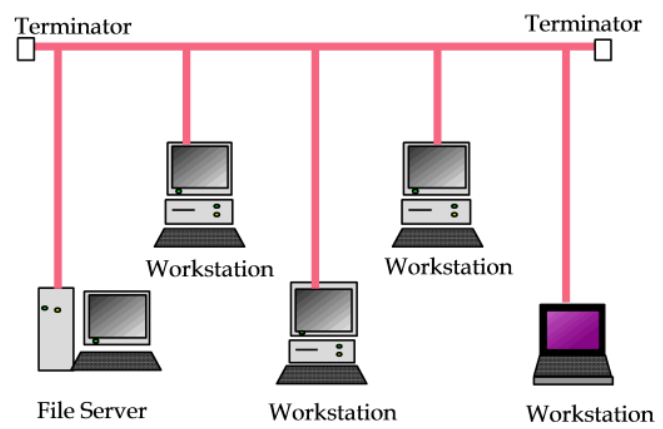

Gambar 2. 1 Toplogi Bus

\section{Topologi Token-Ring}

Metode token-ring (sering disebut ring saja) adalah cara menghubungkan komputer sehingga berbentuk ring (lingkaran). Setiap simpul mempunyai tingkatan yang sama. Jaringan akan disebut sebagai loop, data dikirimkan kesetiap simpul dan setiap informasi yang diterima simpul diperiksa alamatnya apakah data itu untuknya atau bukan.

Topologi ini mempuyai karakteristik sebagai berikut :

a. Lingkaran tertutup yang berisi node-node

b.Sederhana dalam layout.

c. Signal mengalir dalam satu arah, sehingga dapat menghindarkan terjadinya collision (dua paket data bercampur), sehingga memungkinkan pergerakan data yang cepat dan collision detection yang lebih sederhana.

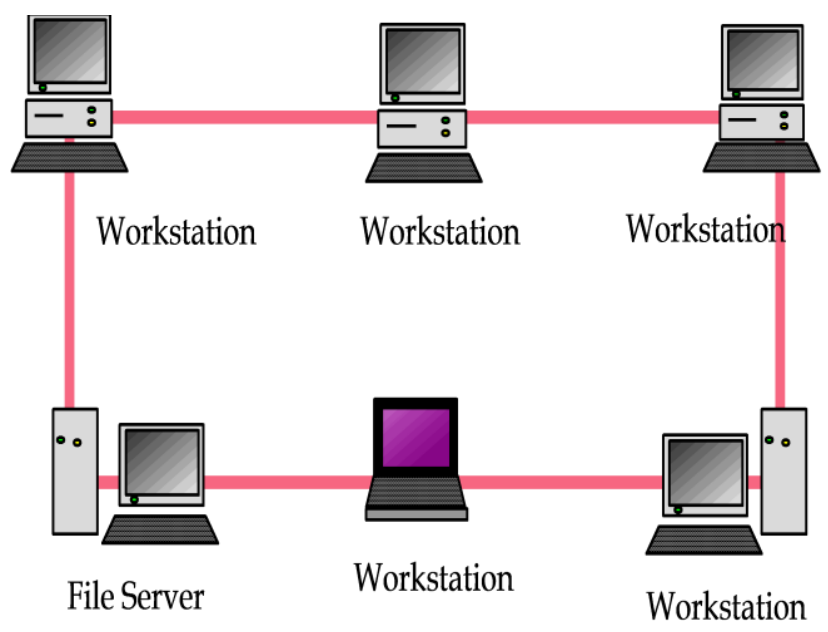

Gambar 2. 2 Topologi Token-Ring

3. Topologi Star

Topologi Star merupakan topologi yang banyak dipergunakan diberbagai tempat, karena kemudahan untuk menambah, mengurangi, atau mendeteksi kerusakan jaringan yang ada. Topologi ini memiliki kontrol terpusat, semua link harus melewati pusat yang menyalurkan data tersebut kesemua simpul atau client yang dipilihnya. Simpul pusat dinamakan stasiun primer atau server dan lainnya dinamakan stasiun sekunder atau client-server. Setelah hubungan jaringan dimulai oleh server maka setiap client-server sewaktu-waktu dapat menggunakan hubungan jaringan tersebut tanpa menunggu perintah dari server. Topologi ini mempunyai karakteristik sebagai berikut :

a. Setiap node berkomunikasi langsung dengan central node, traffic data mengalir dari node ke central node dan kembali lagi. 
b. Mudah dikembangkan, karena setiap node hanya memiliki kabel yang langsung terhubung ke central node.

c. Keunggulannya adalah jika satu kabel node terputus yang lainnya tidak terganggu.

d. Dapat digunakan kabel yang lower grade karena hanya menangani satu traffic node, biasanya digunakan kabel UTP (Unshielded Twisted Pair)

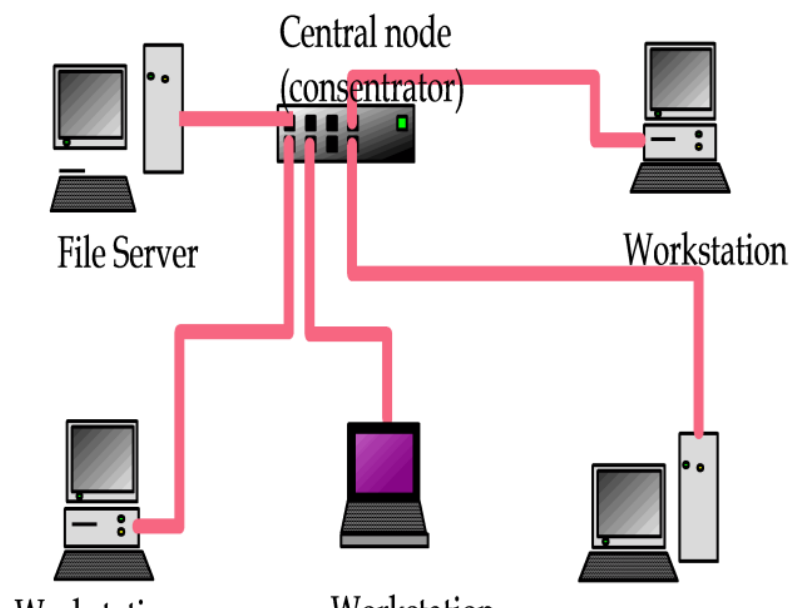

Workstation

Workstation

Workstation

Gambar 2. 3 Topologi Star

\section{III.METODOLOGI PENELITIAN}

VOIP dapat ditempatkan pada berbagai topologi jaringan, untuk merancang sebuah topologi yang tepat pada jaringan VOIP terdapat beberapa hal yang perlu diperhatikan antara lain: lokasi, jarak, dan biaya. Semua kemungkinan yang akan terjadi haruslah dipikirkan oleh admin jaringan tersebut untuk mendapatkan hasil yang optimal.

Dalam perancangan jaringan VOIP sederhana, penulis menggunakan topologi Star dengan menggunakan tiga buah laptop, dimana satu laptop difungsikan sebagai server VOIP menggunakan Asterisk dan dua buah laptop lainnya sebagai client. Semua laptop dihubungkan dalam satu jaringan lokal menggunakan dengan sebuah Switch/Hub. Seperti yang terlihat pada gambar 3.1 dibawah ini :

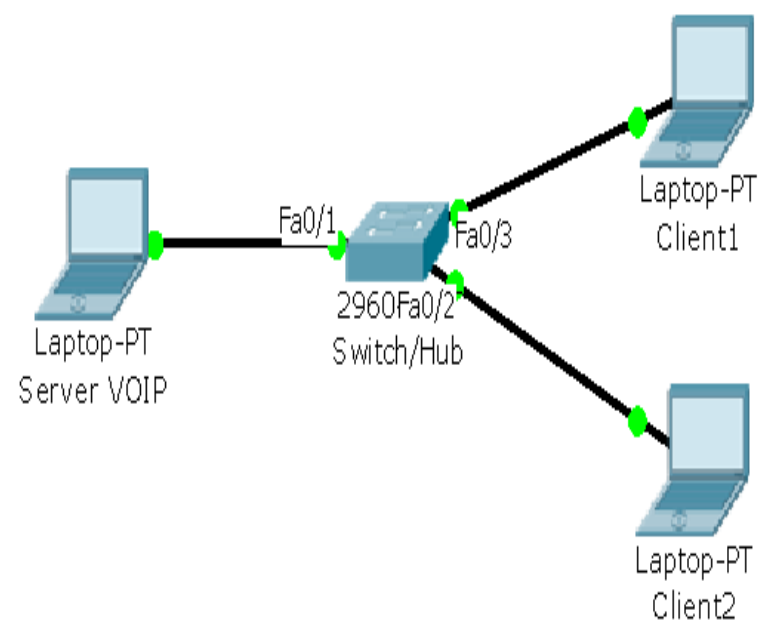

Gambar 3. 1 Konfigurasi koneksi jaringan VOIP

\section{A. Perancangan Jaringan VOIP}

Dalam perancangan jaringan VOIP ini sistem pengalamatan yang digunakan oleh penulis seperti pada tabel berikut:

Tabel 3.1 Sistem pengalamatan jaringan VOIP

\begin{tabular}{|l|c|c|c|}
\hline Nama & $\begin{array}{c}\text { IP } \\
\text { Address }\end{array}$ & $\begin{array}{c}\text { Subnet } \\
\text { Mask }\end{array}$ & Gateway \\
\hline $\begin{array}{l}\text { Server } \\
\text { VOIP }\end{array}$ & 172.16 .10 .30 & 255.255 .255 .224 & 172.16 .10 .1 \\
\hline $\begin{array}{l}\text { Client } \\
01\end{array}$ & 172.16 .10 .29 & 255.255 .255 .224 & 172.16 .10 .1 \\
\hline $\begin{array}{l}\text { Client } \\
02\end{array}$ & 172.16 .10 .28 & 255.255 .255 .224 & 172.16 .10 .1 \\
\hline
\end{tabular}

Block diagram konektifitas pada jaringan VOIP ini adalah sebagai berikut:

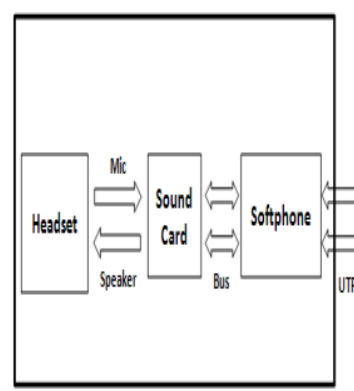

User1

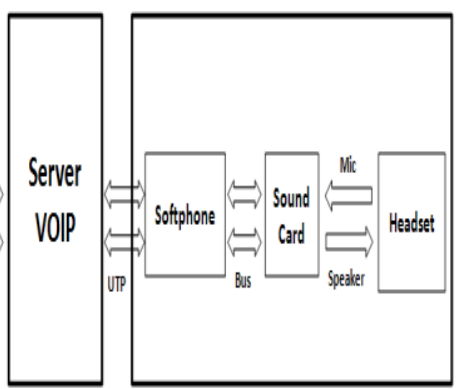

User2

\section{Gambar 3. 2 Blok diagram konektifitas VOIP}

Blok diagram pada gambar 3.2 diatas menjelaskan bagaimana proses koneksi atau sambungan antara user1 dengan user2. Dimana blok diagram tersebut dibagi menjadi tiga bagian yang terdiri dari input, proses, dan output. Input dari user1 berupa headset melalui 
microphone, soundcard dan softphone. Bagian proses ditangani oleh server VOIP yang merupakan sentral telepon dari VOIP. Pada outputnya terdiri dari softphone, soundcard, dan headset melalui speakernya. Disini kita dapat melihat bahwa output dari user1 merupakan input bagi user2, begitu pula sebaliknya.

\section{B. Instalasi dan Konfigurasi Asterisk}

Sebelumnya menginstal paket Asterisk, terlebih dahulu kita perlu untuk meng-update dan upgrade sistem operasi Ubuntu. Namun terlebih dahulu perlu koneksi ke internet dan perlu login sebagai user root atau su (Super User). Jalankan perintah : apt-get update dan apt-get upgrade. Kemudian install paket Asterisk dengan mengetikkan perintah : apt-get install asterisk. Kemudian tekan "Y" untuk melanjutkan instalasi dan tunggu sampai instalasi Asterisk berhasil diinstal. Kemudian Jalankan perintah : gedit /etc/default/asterisk dan rubah bagian RUNASTERISK=YES.

Setelah instalasi Asterisk berhasil maka selanjutnya adalah mengkonfigurasi Asterisk, beberapa yang perlu dilakukan adalah sebagai berikut :

1. Konfigurasi Data Account

Konfigurasi ini digunakan untuk me-registrasi atau penambahan user. Konfigurasi data account dilakukan dengan mengedit file "sip.conf”. File ini berada di lokasi “/etc/asterisk/". File tersebut dapat diedit dengan perintah: gedit /etc/asterisk/sip.conf.

Kemudian konfigurasi data account untuk extension yang dapat ditambahkan pada file ini adalah sebagai berikut :

[general]
context $=$ default
port $=5060$
binaddr $=0.0 .0 .0$
srvlookup=yes
tos $=$ Ox 18
;Untuk mengaktifkan fasilitas Video Call
videosupport=yes
disallow $=$ all
allow $=$ gsm
allow $=$ ilbc
allow=ulaw
allow=alaw
allow $=\mathrm{h} 264$
allow $=\mathrm{h} 261$
allow $=\mathrm{h} 263$
allow $=\mathrm{h} 263 \mathrm{p}$
;client1

[101]

type $=$ friend

username $=101$

secret $=1234$

host=dynamic

$\mathrm{dtmfmode}=\mathrm{rfc} 2833$

rfc2833 composate $=$ yes

callerid="sip00"

context=komdig

canreinvite $=$ no

busylevel=1

limitonpeer=yes

call-limit $=1$

mailbox=101@default

;client2

[102]

type $=$ friend

username $=102$

secret $=1234$

host $=$ dynamic

$\mathrm{dtmfmode}=\mathrm{rfc} 2833$

rfc 2833 composate $=$ yes

callerid="sip01"

context=komdig

canreinvite $=$ no

busylevel=1

limitonpeer=yes

call-limit $=1$

mailbox=102@default

;dan seterusnya.

\section{Konfigurasi Dial Plan}

Dial Plan berfungsi sebagai routing panggilan antar ekstensi, baik yang berada dalam satu IP-PBX 
(lokal) maupun antar IP-PBX, atau biasa disebut dial trunk. Dalam Asterisk, Dial Plan diprogram dalam satu file yang bernama extensions.conf.

Secara umum, setiap ekstensi dalam Asterisk merujuk pada user tertentu yang ter-register ke Asterisk tersebut sehingga biasanya nomor ekstensi sama dengan id user.

Untuk mengkonfigurasi dial plan jalankan perintah : gedit /etc/asterisk/extensions.conf. Kemudian ketik perintah di bawah ini :

$$
\begin{aligned}
& \text {;Dial antar ekstensi pada IP-PBX } \\
& \text { [komdig] } \\
& \text { exten }=>\text { 101,1,Dial(SIP/101,20,rt) } \\
& \text { exten }=>\text { 101,2,voicemail }(101) \\
& \text { exten }=>\text { _101,3,Hangup } \\
& \text { exten }=>\text { 101,102,voicemail(101) } \\
& \text { exten }=>\text { 102,1,Dial(SIP/102,20,rt) } \\
& \text { exten }=>\text { 102,2,voicemail(102) } \\
& \text { exten }=>\text { 102,3,Hangup } \\
& \text { exten }=>\text { _102,102, voicemail(102) }
\end{aligned}
$$

\section{IV.HASIL DAN PEMBAHASAN}

Client1 VOIP yang menggunakan Softphone X-lite dengan nomor ekstensi "101" berhasil melakukan proses pemanggilan (Calling) ke Client2 VOIP yang menggunakan Softphone X-lite dengan nomor ekstensi "102”. Berikut tampilan saat proses pemanggilan (Calling) pada Client1 :.

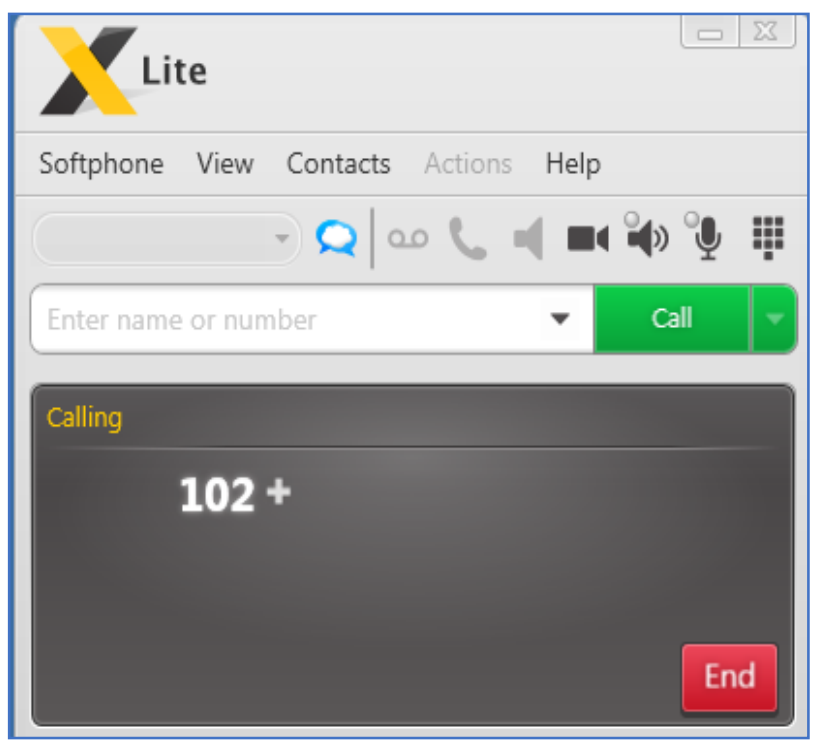

Gambar 4. 1 Tampilan client1 saat proses calling
Sedangkan pada CLI Asterisk di VOIP Server, data dilihat pesan yang menyatakan extension '101' melakukan panggilan dan di jawab oleh extension ' 102 ' seperti terlihat pada gambar berikut :

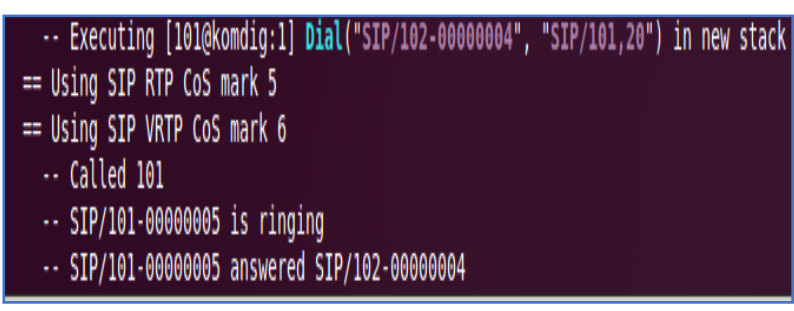

Gambar 4. 2 Proses calling dan incoming call pada

\section{CLI}

Pada saat proses panggilan berlansung, client VOIP dapat melakukan proses Hold dan dapat pula menambahkan penerima lain untuk melakukan conference call. Tampilan fitur Hold dan Conference Call tersebut di salah satu Client seperti pada gambar berikut :

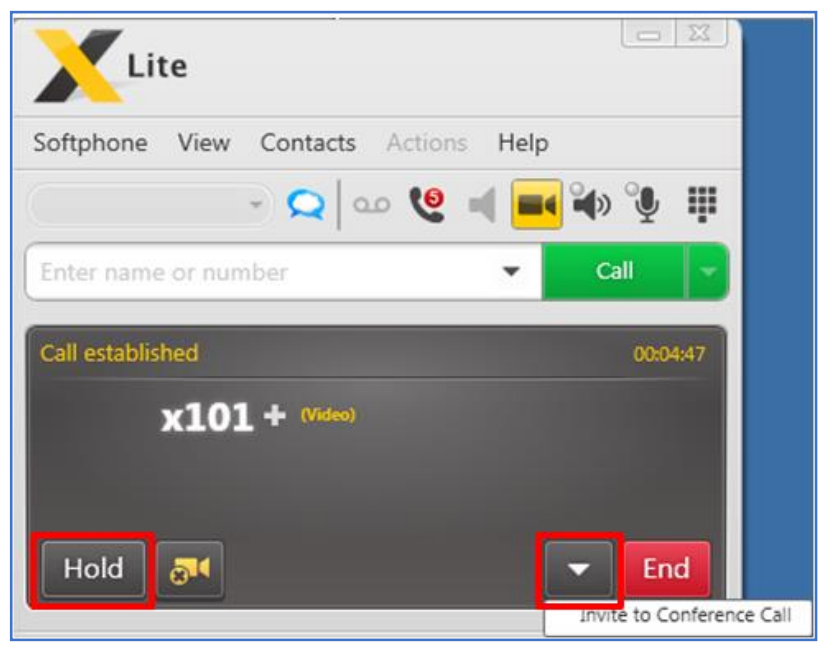

Gambar 4. 3 Menu Hold dan Conference Call di X-

Lite

Jika client VOIP sedang dalam proses panggilan, tapi client VOIP yang lain menghubungi client tersebut, maka server VOIP akan mendeteksinya dan memberikan nada sibuk (busy tone) pada client yang sedang menghubungi tersebut. Berikut tampilan pada salah satu client saat panggilan tidak dilanjutkan karena sedang melakukan panggilan, penulis mencoba dengan melakukan panggilan ke nomor client yang sedang melakukan panggilan tersebut : 


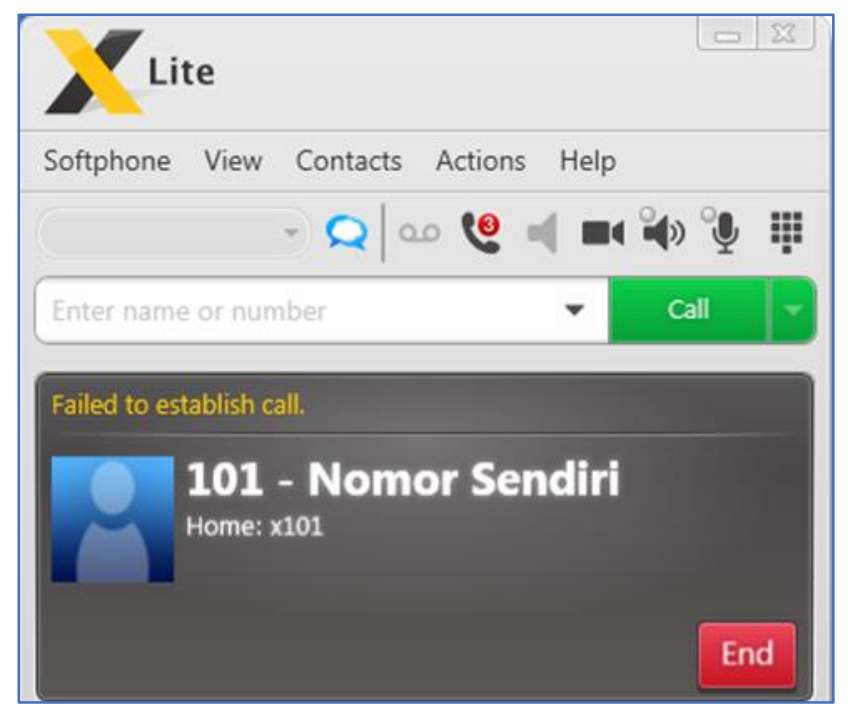

Gambar 4. 4 Panggilan client ke nomor ektensinya

\section{sendiri}

Sedangkan pada CLI Asterisk di server terlihat seperti berikut:

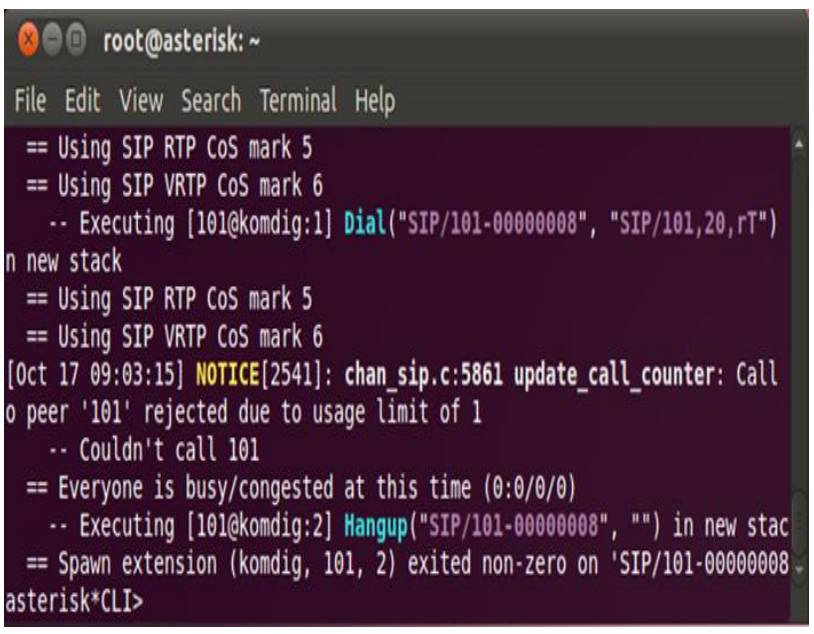

Gambar 4.5 Tampilan proses busydetect pada

\section{Asterisk}

Jika salah client menghubungi nomor ektensi "111" yang digunakan penulis sebagai nomor untuk fitur MeetMe Conference, maka akan terdengar suara yang dimunculkan oleh server VOIP yang memerintahkan untuk memasukkan nomor ID dari meeting yang akan dilaksanakan tersebut sehingga sistem keamanannya lebih baik dan peserta meeting dapat menghubunginya dari nomor ektensi manapun. Berikut tampilan di salah client saat proses fitur MeetMe Conference :

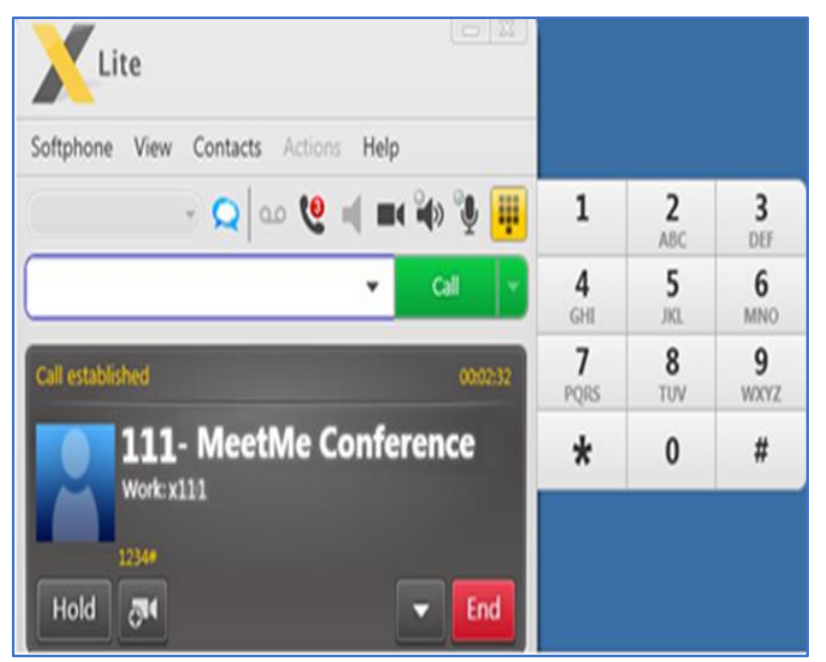

Gambar 4.61 Tampilan client pada proses MeetMe

Conference

\section{KESIMPUlaN DAN SARAN}

Dengan segala potensi yang ada terutama sekali dari segi biaya yang relatif murah untuk berkomunikasi, komunikasi VOIP dengan SIP Asterisk ini sangat berpotensi dikembangkan. VOIP dapat memanfaatkan infrastruktur komputer dan jaringan yang sudah ada untuk berkomunikasi seperti layaknya menggunakan telepon biasa dan tidak dikenakan biaya telepon biasa. Data suara diubah menjadi kode digital dan dialirkan melalui jaringan yang mengirimkan paket-paket data. Penggunaan bandwidth untuk panggilan suara pada VOIP lebih kecil daripada bandwidth yang terpakai pada telepon biasa.

Adapun saran yang dapat diberikan penulis kepada pembaca yang ingin mengembangkan atau melanjutkan teknologi VOIP dengan Asterisk ini adalah sebagai berikut :

1. Bagi yang ingin mengembangkan teknologi VOIP ini, hendaknya juga diimplementasikan untuk client berupa HardPhone seperti IP Phone ataupun unit telepon biasa dengan menggunakan DAC (Digital to Analog Converter).

2. Bagi yang ingin mengembangkan teknologi VOIP ini, hendaknya juga hendaknya VOIP dapat diintegrasikan ke nomor ekstensi VOIP lain, baik dalam jaringan lokal maupun jaringan internet.

3. Diharapkan teknologi VOIP ini tidak hanya berkembang pada lingkungan akademis tetapi dapat juga dikembangkan pada masyarakat luas pada umumnya 
dikarenakan sudah menjamurnya teknologi internet pada saat ini.

\section{Daftar Pustaka}

[1] Bowo, Eri. 2010. Ubuntu from Zero. Jakarta: Jasakom.

[2] Cipto. 2011. Membuat Server VoIP Sederhana Dengan Asterisk. Diambil dari: http://cipto.net/membuat-server-voip-sederhanadengan-asterisk. (22 Septermber 2012).

[3] Purbo, Onno W. 2008. Panduan Mudah Merakit dan Menginstal Server Linux. Yogyakarta. CV. Andi.

[4] Purbo, Onno W. 2012. Instalasi Asterisk di Ubuntu. Diambildari: http://opensource.telkomspeedy.com/wiki/index.php /Instalasi_Astersik_di_Ubuntu. (10 September 2012)

[5] Pusat Bahasa Departemen Pendidikan Nasional. 2008. Kamus Bahasa Indonesia. Jakarta: Pusat Bahasa.

[6] Pusat Pembinaan dan Pengembangan Bahasa Departemen Pendidikan dan Kebudayaan. 2009. Pedoman Umum Ejaan Bahasa Indonesia yang Disempurnakan. Jakarta: Pusat Bahasa.

[7] Rafiudin,Rahmat. 2006. IP Routing dan Firewall dalam Linux. Yogyakarta: CV. Andi.

[8] Sopandi, Dede. 2005. Instalasi dan konfigurasi jaringan komputer. Bandung: Informatika.. 